\title{
Suppression of the photoparoxysmal response in photosensitive epilepsy with cenobamate (YKP3089)
}

Dorothee G.A. Kasteleijn- Nolst Trenite, MD, PhD, MPH, Bree D. DiVentura, MBA, John R. Pollard, MD, Gregory L. Krauss, MD, Sarah Mizne, PharmD, and Jacqueline A. French, MD

Neurology ${ }^{\circledR}$ 2019;93:e559-e567. doi:10.1212/WNL.0000000000007894

\section{Abstract}

\section{Objective}

To evaluate the effect of cenobamate in patients with photoparoxysmal-EEG response (PPR) to intermittent photic stimulation (IPS) as proof of principle of efficacy in patients with epilepsy.

\section{Methods}

In this multicenter, single-blind study, adults with photosensitive epilepsy, with/without concomitant antiepileptic drug therapy, underwent IPS under 3 eye conditions after a single dose of placebo (day -1 , day 2) or cenobamate (day 1; 100, 250, or $400 \mathrm{mg}$ ). Complete suppression was a standardized photosensitivity range reduction to 0 over $\geq 1$ time points for all eye conditions. Partial suppression was a $\geq 3$-point reduction over $\geq 3$ testing times vs the same time points on day -1 in $\geq 1$ eye condition. Pharmacokinetics and safety were assessed.

\section{Results}

Of 6 evaluable patients, 5 reentered to receive higher doses. Cenobamate $100 \mathrm{mg}$ produced partial suppression in 1 of 3 patients; $250 \mathrm{mg}$ produced complete suppression in 1 of 4 and partial suppression in 4 of 4 patients; and $400 \mathrm{mg}$ produced complete suppression in 1 of 4 and partial suppression in 2 of 4 patients. PPR was consistently reduced on days 1 and 2 (>24 hours after cenobamate) vs day -1 (placebo) with the 250- and 400-mg doses. Area under the plasma concentration-time curve (before dose to last measurable concentration) values between 201 and $400 \mu \mathrm{g} / \mathrm{h} / \mathrm{mL}$ resulted in partial suppression in 4 of 6 (66\%) patients. Most common adverse events were dizziness and somnolence.

\section{Conclusions}

This proof-of-principle study demonstrated that cenobamate is a potentially effective product for epilepsy.

\section{ClinicalTrials.gov identifier NCT00616148.}

\section{Classification of evidence}

This study provides Class III evidence that, for patients with photosensitive epilepsy, cenobamate suppresses IPS-induced PPR.

\author{
Correspondence \\ Dr. Kasteleijn-Nolst Trenite \\ dkasteleijn@planet.nl
}

\section{MORE ONLINE}

$\rightarrow$ Class of Evidence

Criteria for rating

therapeutic and diagnostic

studies

NPub.org/coe 


\section{Glossary}

$\mathrm{AE}=$ adverse event; $\mathbf{A E D}=$ antiepileptic drug; $\mathbf{A U C}=$ area under the plasma concentration vs time curve; IPS = intermittent photic stimulation; ITT = intent-to-treat; PPR = photoparoxysmal response; $\mathbf{P R}=$ photosensitivity range; $\mathbf{S P R}=$ standardized photosensitivity range; TEAE $=$ treatment-emergent adverse event.

In patients with photosensitive epilepsy, intermittent photic stimulation (IPS) typically results in a characteristic epileptiform response on EEG. ${ }^{1,2}$ Photosensitivity or the IPS-induced photoparoxysmal response (PPR) on EEG is commonly associated with generalized epilepsies but can also occur in patients with focal epilepsy. ${ }^{3,4}$ Standardized assessment of the PPR can be used as a proof-of-principle model for the assessment of investigational antiepileptic drugs (AEDs) in early clinical development. ${ }^{1,5,6}$

In the model, photosensitive patients are exposed to IPS, and a reduction in sensitivity to the number of standard visual stimulation frequencies after a single, acute dose of a potential AED is used as an endpoint. ${ }^{7}$ The standardized photosensitivity range (SPR) is a reliable screening method for assessing AED efficacy and safety ${ }^{2}$ and can inform dose selection for larger clinical trials. ${ }^{7}$

Cenobamate (YKP3089) is a novel AED under investigation for use in patients with focal (partial-onset) seizures. It has been shown to modulate several properties of voltage-gated sodium channels and to preferentially inhibit persistent sodium currents. ${ }^{8}$ Preclinical data indicate a broad spectrum of anticonvulsant activity in rodent seizure and epilepsy models. ${ }^{9-11}$ The purpose of this study was to evaluate the effect of cenobamate on the IPS-induced EEG PPR in patients with photosensitive epilepsy as proof of concept of its antiepileptic effects.

\section{Methods}

\section{Patients}

Male or female patients 18 to 60 years of age with a body mass index of 18 to $35 \mathrm{~kg} / \mathrm{m}^{2}$ and diagnosis of epilepsy who were stabilized on 0 to 2 concomitant AEDs for at least 4 weeks before the start of the study were eligible for study inclusion. If a patient was taking 2 concomitant medications, the second drug had to be levetiracetam, gabapentin, or pregabalin. Eligible patients also had to have a reproducible IPS-induced PPR on EEG of $\geq 3$ points on a frequency assessment scale in $\geq 1$ eye conditions (eyes open, eye closure, and/or eyes closed) and no change of $>3$ frequencies in 2 repeated measurements recorded over the 2 months before study entry in $\geq 1$ eye conditions. Patients were excluded from the study if they had a history of nonepileptic seizures; were pregnant or lactating or were of reproductive potential but chose not to adhere to effective birth control methods; had CNS, neurologic, or psychiatric conditions considered to be progressive during the course of the study; or were at risk for liver adverse events (AEs), including drug-drug interactions (cytochrome $\mathrm{p} 450)$.

\section{Study design}

This phase $2 \mathrm{a}$, single-blind, single-dose, multicenter study enrolled and evaluated adult patients with photosensitive epilepsy in 4 medical centers in the United States from August 20, 2007, to January 26, 2009, under the auspices of the Epilepsy Study Consortium. The clinical portion was singleblinded in that only the patients were blinded to the study treatments. However, after the clinical portion was completed, EEG data were sent to a blinded clinical expert for interpretation.

Four sequential doses of cenobamate were intended to be evaluated per the initial protocol: 100, 250, 400, and $600 \mathrm{mg}$. Three to 6 patients were recruited sequentially for each dose cohort. Once a cohort was completed, the next higher dose cohort was recruited. Patients who completed a lower dose could be recruited into a higher dose cohort. Patients must have received a $100-\mathrm{mg}$ dose followed by an observation period of 48 hours to be eligible to receive the next sequential dose $(250 \mathrm{mg})$, and so on with each subsequent dose cohort (250-mg dose before 400-mg dose, etc). A washout period of at least 2 weeks was also required before a patient could receive a higher dose (2-week washout after an observation period and 4-week washout after hospitalization and IPS). Patients screened within 21 days were admitted for IPS testing and remained onsite for at least 4 days, including a 48-hour observation period after administration of the first cenobamate dose $(100 \mathrm{mg})$. Patients received a dose of placebo on day -1 (baseline), a single oral dose of cenobamate on day 1 , and placebo again on day 2 to maintain the single blind and to allow assessment of the duration of effect after cenobamate. ${ }^{12}$ If there was a continued treatment effect on the IPS response after the 30 -hour post-cenobamate dose IPS assessment, the patient underwent additional daily IPS evaluations with simultaneous blood draws for pharmacokinetic testing and AED levels until there was no treatment effect and the IPS response returned to baseline. All medication was administered under direct supervision.

A Data Safety Monitoring Board reviewed cenobamate plasma levels after exposure to the lower dose level before patients were exposed to the higher dose level. Patients who achieved cenobamate plasma levels consistent with those observed in previous studies of phase 1 volunteers were permitted to participate at the higher dose level, provided that they had not experienced any intolerable side effects. This safeguarded against exposing patients to higher dose levels 
who may have experienced pharmacokinetic interactions between their AEDs and cenobamate.

Dosing was not to be increased to the next dose level if 2 of 3 patients experienced a moderate $\mathrm{AE}$ at the prior cenobamate dose level or if any patient experienced a serious $\mathrm{AE}$ that was considered related to treatment. Patients could withdraw from the study at any time. In addition, patients would be withdrawn if they experienced a predefined widening of the photosensitivity range (PR), unexpected tonicclonic seizures during IPS, or evidence of proconvulsive activity on EEG.

\section{Photic stimulation procedures}

The photosensitivity model has been described extensively. ${ }^{1-3,12,13}$ In this model, patients are exposed to IPS before and after placebo/AED intake at hourly intervals over a 3-day period. A standardized stimulation protocol is used to establish photosensitivity thresholds (in Hertz), which are translated into an SPR value in points.

PPR step ranges were determined for 3 eye conditions (eye closure, eyes closed, and eyes open) before and 1, 2, 3.5, 5, 6.5, and 8 hours after dose on days $-1,1$, and 2 , and before and 2 and 6 hours after dose on day 3 . Flashes were administered at 14 standard frequencies of $2,5,8,10,13,15,18,20,23,25,30$, 40,50 , and $60 \mathrm{~Hz}$ that were converted to SPRs. SPR was expressed as the categorical number of standard frequencies for which a PPR was elicited, ranging from 0 to 14 , with 0 defined as no PPR elicited at any flash frequencies and 14 defined as PPR elicited in all flash frequencies. Upper and lower limit frequencies triggering a PPR and derived SPR were recorded by eye condition, patient number, visit, and time point for each treatment.

\section{Pharmacokinetics}

Blood samples for pharmacokinetic evaluations of cenobamate were collected before dose on day 1 and at 1, 2, 3.5, 5, $6.5,8,23.5,24,25,26,27.5,29,30.5,32,48,50$, and 54 hours after dose. The following pharmacokinetic parameters were calculated for cenobamate: the area under the plasma concentration vs time curve (AUC) from time 0 to 24 hours after dose $\left(\mathrm{AUC}_{0-24}\right)$ and the AUC from time 0 on day 1 to the last measurable concentration $\left(\mathrm{AUC}_{0-\mathrm{t}}\right)$ using the linear trapezoidal method; the AUC from time 0 on day 1 to infinity $\left(\mathrm{AUC}_{0 \text {-inf }}\right)$; the $\mathrm{AUC}_{0-\mathrm{t}} / \mathrm{AUC}_{0 \text {-inf }}$ ratio; the maximum measured drug plasma concentration $\left(\mathrm{C}_{\max }\right)$; the time of maximum measured plasma concentration $\left(t_{\max }\right)$; the apparent first-order terminal elimination rate constant $\left(\mathrm{k}_{\mathrm{el}}\right)$; and the apparent elimination half-life $\left(t_{1 / 2}\right)$.

AED treatment was recorded throughout the study, and blood samples were collected at each visit to measure concomitant AED levels. Specifically, blood samples were collected at the screening visit and on day -1 , day 1 , and day 2 before dose (trough levels) and 1, 2, 3.5, 5, 6.5, 8, and 24 hours after dose. Additional samples were drawn on day 3 at 26 and 30 hours after dose. Pharmacokinetic parameters calculated for plasma AEDs were $\mathrm{AUC}_{0-24}, \mathrm{C}_{\max }$ and $\mathrm{t}_{\max }$.

\section{Safety}

AEs, as reported spontaneously by the patient or observed by the investigator, were recorded over the course of the trial. Safety was also monitored via vital signs, clinical laboratory values, changes in physical examination, EEG, and administration of the Bond and Lader ${ }^{14}$ Mood Visual Analog Scale.

\section{Statistical methods}

The intent-to-treat (ITT) population included all patients who received at least 1 dose of study medication (placebo or cenobamate) and had at least 1 postbaseline assessment. The safety population included all patients who received at least 1 dose of study medication.

Upper and lower limit frequencies triggering a PPR and derived SPR were summarized with descriptive statistics. Specifically, the IPS-induced PPR quantified in terms of a PR (also referred to as PPR step ranges) were determined for the 3 eye conditions. Complete and partial suppression of PPR, defined as change of SPR, was determined for each eye condition, in addition to determination of the most sensitive eye (defined as the eye condition with the largest PR on day -1 across all time points) for each patient at each dose level on days 1 and 2 and overall. The difference in SPR for days 1 to 3 vs the corresponding time points on day -1 (placebo) was also summarized with descriptive statistics.

Complete suppression was defined as the reduction of the SPR to 0 over $\geq 1$ testing time points for all 3 eye conditions within the same day if the baseline PPR at the same time point for each eye condition was $>0$. Partial suppression was defined as a reduction in SPR by $\geq 3$ points over $\geq 3$ testing times within 1 day compared to the range at the same time points on placebo day (day -1). If a patient had a tie for the largest average value of SPR, the priority for the most sensitive eye condition was eye closure $>$ eyes closed $>$ eyes opened.

Plasma concentration and pharmacokinetic data for cenobamate and the AEDs were summarized by cohort with descriptive statistics (sample size, arithmetic mean, SD, percent coefficient of variation, and geometric mean, median, minimum, and maximum values). In addition, geometric percent coefficient of variation was presented for the pharmacokinetic parameter data.

\section{Standard protocol approvals, registrations, and patient consents}

The study protocol and informed consent forms were reviewed and approved by the institutional review boards at each investigational center. Before initiation of any studyspecific procedures, patients were provided written informed consent that summarized the purpose of the study, procedures of the study, and potential risks of the study (ClinicalTrials.gov identifier NCT00616148). This study was 
conducted in accordance with the principles and requirements described in the International Conference on Harmonization Consolidated Guidelines on Good Clinical Practice and the Declaration of Helsinki.

\section{Classification of evidence}

The primary research question of this phase 2, single-blind, controlled study was whether single-dose cenobamate has an effect on the IPS-induced PPR EEG response in patients with photosensitive epilepsy as proof of principle for cenobamate clinical activity in epilepsy. The nonrandomized study provided Class III evidence that cenobamate (100, 250, and $400 \mathrm{mg}$ ) suppressed IPS response compared with baseline, with greater suppression observed at the 250- and 400-mg doses.

\section{Data availability}

The data for the analyses described in this article are available by request from the author investigators or SK Life Sciences, Inc, the company sponsoring the clinical development of cenobamate for the treatment of focal epilepsy.

\section{Results}

Overall, 7 patients were enrolled and received $\geq 1$ dose of study medication during the trial (figure 1). Of the 7 patients, 5 reentered the study to participate at a higher dose level. Patients were given new identifiers when they reentered the study. After the sequential assessments of the 250-mg and 400-mg dose groups, the study was stopped early, before

\section{Figure 1 Patient disposition}

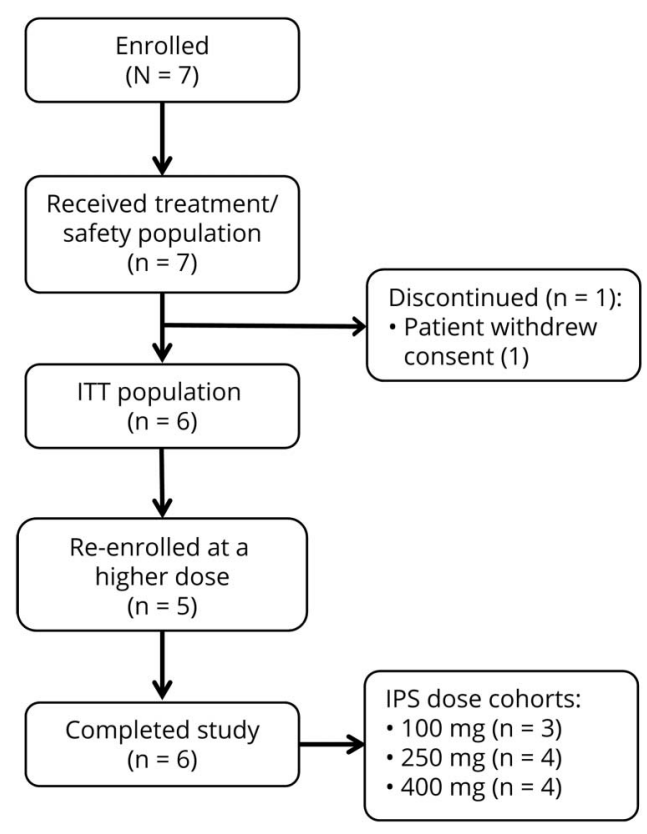

Seven patients enrolled in the study and received treatment. One patient withdrew consent after a 100-mg dose of cenobamate before intermittent photic stimulation (IPS) assessment. Five patients re-enrolled and progressed to a higher dose. ITT = intent to treat. enrollment of patients at the 600-mg dose, because overall patient enrollment was low and this dose group was no longer deemed necessary. One patient was discontinued from the study after withdrawal of consent. This patient discontinued after a single dose of 100-mg cenobamate but did not undergo IPS assessment and therefore was not included in the ITT analysis. In the ITT population, there were 3 evaluable patients at the 100-mg dose level and 4 evaluable patients in each of the 250- and 400-mg dose levels.

Demographics were similar for patients in the 3 dosing cohorts (table 1). The patient ages ranged from 19 to 28 years. All were white; most patients ( 5 of 7 ) were female. Of the 7 patients, 6 had a history of generalized seizures, and 1 patient had a history of focal seizures. ${ }^{15}$ All but 1 patient took ongoing concomitant AEDs during this study (table 1).

The results of photic stimulation in each eye condition are summarized in table 2. At the $100-\mathrm{mg}$ dose level $(n=3)$, cenobamate produced partial suppression of IPS sensitivity in $1(33 \%)$ patient in the eyes closed condition (patient 2, day $1)$. At the $250-\mathrm{mg}$ dose level $(\mathrm{n}=4)$, cenobamate produced complete suppression of IPS sensitivity in 1 (25\%) patient (patient 5, day 2). In addition, at this dose, partial suppression of IPS sensitivity was observed in all patients $(n=4)$ in at least 1 eye condition, including $3(75 \%)$ patients with partial suppression of IPS in the most sensitive eye condition (patients 5 and 6, day 2; patient 7, days 1 and 2) (table 2). At the 400-mg dose level $(n=4)$, cenobamate produced complete suppression of IPS sensitivity in $1(25 \%)$ patient (patient 12 , days 1 and 2), and partial suppression was observed in 2 (50\%) patients in at least 1 eye condition (patient 12 , days 1 and 2 ; patient 11 , day 2 ) (table 2 ).

At 1 hour after dosing, PPR was consistently reduced with 250and 400-mg cenobamate on days 1 and 2 compared with placebo (day -1 ) for the most sensitive eye condition (figure 2).

The mean plasma cenobamate concentration-time profile for each dose cohort is shown in figure 3. On the basis of the geometric mean values, the $\mathrm{AUC}_{0-24}$ and $\mathrm{C}_{\max }$ of cenobamate appeared to increase proportionate to dose across the 3 dose levels (table 3 ). The $\mathrm{AUC}_{0-\mathrm{t}}$ of cenobamate increased with increasing dose level but not in linear proportion to the dose administered. The $\mathrm{AUC}_{0 \text {-inf }}$ of cenobamate appeared to increase in a more than dose-proportional fashion from the 100 $\mathrm{mg}$ to the 250-mg dose level but dose-proportionally from the 250 -mg to the 400-mg dose level. The $\mathrm{t}_{1 / 2}$ of cenobamate was shorter at the 100-mg dose level than at the 250- and 400-mg dose levels, with these 2 dose levels exhibiting a similar $t_{1 / 2}$. The $\mathrm{AUC}_{0-\mathrm{t}} / \mathrm{AUC}_{0 \text {-inf }}$ ratio was low for all 3 doses, indicating that a large portion of the overall exposure $\left(\mathrm{AUC}_{0 \text {-inf }}\right)$ was extrapolated. The median $t_{\max }$ of cenobamate was different for all 3 dose levels and ranged from 2.77 to 7.91 hours.

Higher cenobamate $\mathrm{C}_{\max }$ concentrations and $\mathrm{AUC}_{0-\mathrm{t}}$ resulted in greater suppression of IPS response (table 4), with the 
Table 1 Patient demographic characteristics and concomitant AEDs

\begin{tabular}{|c|c|c|c|c|}
\hline \multirow[b]{2}{*}{ Demographic variable } & \multicolumn{3}{|c|}{ Cenobamate treatment dose } & \multirow{2}{*}{$\begin{array}{l}\text { Total (unique patients) } \\
(\mathbf{N}=7)\end{array}$} \\
\hline & $100 \mathrm{mg}(\mathrm{n}=4)$ & $250 \mathrm{mg}(n=4)$ & $400 \mathrm{mg}(\mathrm{n}=4)$ & \\
\hline Age $( \pm S D)$ [minimum-maximum], y & $20.5( \pm 3.0)[19-25]$ & $23.0( \pm 3.9)[19-28]$ & $21.5( \pm 1.9)[20-24]$ & $22.1( \pm 3.6)[19-28]$ \\
\hline $\begin{array}{l}\text { Height }( \pm S D) \text { [minimum-maximum], } \\
\text { cm }\end{array}$ & $\begin{array}{l}170.7( \pm 6.1) \\
{[162.6-177.0]}\end{array}$ & $\begin{array}{l}164.5( \pm 5.9) \\
{[156.2-170.2]}\end{array}$ & $\begin{array}{l}169.6( \pm 11.8) \\
{[155.0-180.3]}\end{array}$ & $\begin{array}{l}167.2( \pm 6.9) \\
{[156.2-177.0]}\end{array}$ \\
\hline $\begin{array}{l}\text { Weight }( \pm S D) \text { [minimum-maximum], } \\
\text { kg }\end{array}$ & $62.3( \pm 3.4)[59.1-65.5]$ & $61.6( \pm 16.9)[44.5-83.6]$ & $56.4( \pm 8.9)$ [44.0-63.5] & $61.5( \pm 12.1)$ [44.5-83.6] \\
\hline $\begin{array}{l}\text { BMI ( } \underset{2}{2} \mathrm{SD}) \text { [minimum-maximum], } \\
\mathrm{kg} / \mathrm{m}^{2}\end{array}$ & $21.5( \pm 2.6)$ [18.9-24.7] & $22.6( \pm 5.4)[18.2-30.2]$ & $19.5( \pm 1.0)[18.3-20.6]$ & $22.0( \pm 4.3)[18.2-30.2]$ \\
\hline Male, n (\%) & $2(50)$ & 0 & $2(50)$ & $2(28.6)$ \\
\hline Female, n (\%) & $2(50)$ & $4(100)$ & $2(50)$ & $5(71.4)$ \\
\hline \multicolumn{5}{|l|}{ Ethnic origin, $\mathbf{n}(\%)$} \\
\hline White & $4(100)$ & $4(100)$ & $4(100)$ & $7(100)$ \\
\hline \multicolumn{5}{|l|}{ Epilepsy class, n (\%) } \\
\hline Focal & 0 & $1(25)$ & 0 & $1(14.3)$ \\
\hline Generalized & $4(100)$ & $3(75)$ & $4(100)$ & $6(85.7)$ \\
\hline \multicolumn{5}{|l|}{ Concomitant AED, n (\%) } \\
\hline Ethosuximide & $0(0)$ & $1(25)$ & $1(25)$ & $1(14.3)^{a}$ \\
\hline Levetiracetam & $3(75)$ & $3(75)$ & $2(50)$ & $5(71.4)^{a}$ \\
\hline Topiramate & $0(0)$ & $1(25)$ & $0(0)$ & $1(14.3)^{a}$ \\
\hline Valproic acid & $2(50)$ & $0(0)$ & $2(50)$ & $2(28.6)^{a}$ \\
\hline
\end{tabular}

Abbreviations: $A E D=$ anti-epileptic drug; $B M I$ = body mass index.

a Denominator is 7 unique patients. Two unique patients received both levetiracetam and valproic acid; 2 unique patients received both ethosuximide and levetiracetam.

Table 2 Overall proportion of patients administered each dose of cenobamate experiencing complete suppression, partial suppression, or no change in IPS sensitivity vs day -1 (placebo)

\begin{tabular}{|c|c|c|c|}
\hline \multirow[b]{2}{*}{ Response, $n$ (\%) } & \multicolumn{3}{|c|}{ Cenobamate treatment dose, $\mathrm{n}(\%)$} \\
\hline & $100 \mathrm{mg}(\mathrm{n}=3)$ & $250 \mathrm{mg}(\mathrm{n}=4)$ & $400 \mathrm{mg}(n=4)$ \\
\hline Complete suppression ${ }^{a}$ & $0(0)$ & $1(25)$ & $1(25)$ \\
\hline \multicolumn{4}{|l|}{ Partial suppression ${ }^{b}$} \\
\hline Eye closure & $0(0)$ & $2(50)$ & $1(25)$ \\
\hline Eyes closed & $1(33)$ & $3(75)$ & $1(25)$ \\
\hline Eyes opened & $0(0)$ & $1(25)$ & $0(0)$ \\
\hline Most sensitive eye condition & $0(0)$ & $3(75)$ & $1(25)$ \\
\hline Complete or partial suppression in the most sensitive eye condition & $0(0)$ & $3(75)$ & $1(25)$ \\
\hline No change ${ }^{c}$ & $2(66.7)$ & $0(0)$ & $2(50)$ \\
\hline \multicolumn{4}{|c|}{$\begin{array}{l}\text { Abbreviation: IPS = intermittent photic stimulation. } \\
\text { Patients are not mutually exclusive among the } 3 \text { eye conditions. The most sensitive eye condition is defined as the eye condition with the largest photo- } \\
\text { sensitivity range on day }-1 \text { averaged across all time points. } \\
\text { a Complete suppression = standardized photosensitivity range reduced to } 0 \text { over } \geq 1 \text { testing time points for all } 3 \text { eye conditions within the same day if baseline } \\
\text { photoparoxysmal response at the same time point for each eye condition was }>0 \text {. } \\
\text { b Partial suppression = standardized photosensitivity range reduced by } \geq 3 \text { points over } \geq 3 \text { testing times within } 1 \text { day compared to the range at the same time } \\
\text { points on placebo day (day }-1 \text { ). } \\
{ }^{c} \text { No change = patients who do not have either complete or partial suppression in any eye condition. }\end{array}$} \\
\hline
\end{tabular}


Figure 2 One-hour SPR (mean \pm SD) on day -1 and changes in SPR on days 1 and 2 vs day -1

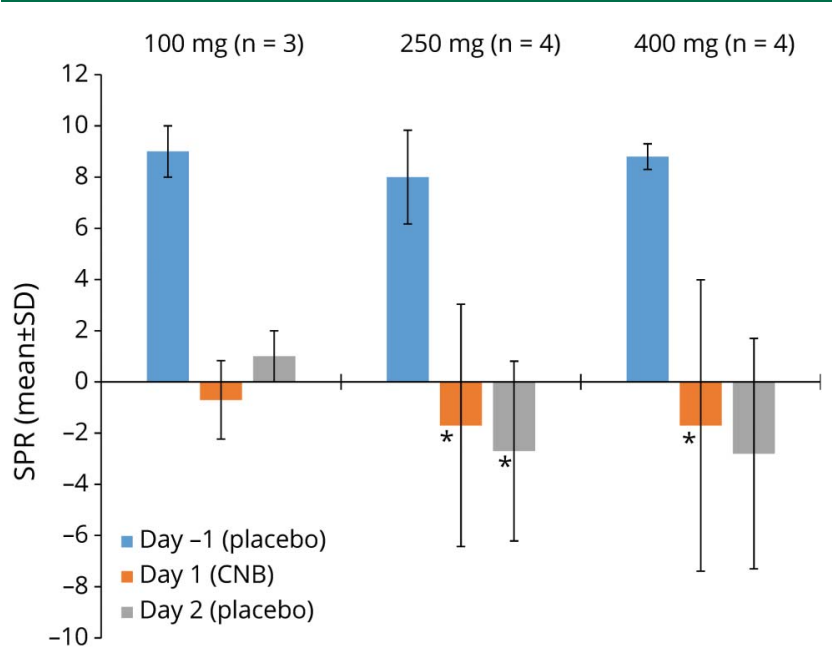

One-hour standardized photosensitivity range (SPR) (mean \pm SD) on day -1 (placebo) and mean \pm SD changes in SPR on days 1 and 2 (after cenobamate [CNB]) vs day -1 for the most sensitive eye condition. ${ }^{*} n=3$.

caveat that only a small number of patients were evaluated. For example, $C_{\max }$ values in the range of 1.0 to $4.0 \mu \mathrm{g} / \mathrm{mL}$ resulted in partial suppression of IPS sensitivity in 1 of $3(33 \%)$ patients; $C_{\max }$ values in the range of 4.1 to $9.0 \mu \mathrm{g} / \mathrm{mL}$ resulted in partial suppression of IPS sensitivity in 4 of 6 (66\%) patients; and $C_{\max }$ values in the range of 9.1 to $16.0 \mu \mathrm{g} / \mathrm{mL}$ resulted in complete suppression in 2 of 2 (100\%) patients. Similarly, $\mathrm{AUC}_{0-\mathrm{t}}$ values in the range of 1 to $200 \mu \mathrm{g} / \mathrm{h} / \mathrm{mL}$ resulted in partial suppression of IPS sensitivity in 1 of 3 patients $(33 \%)$; $\mathrm{AUC}_{0-\mathrm{t}}$ values in the range of 201 to $400 \mu \mathrm{g} / \mathrm{h} / \mathrm{mL}$ resulted in partial suppression of IPS sensitivity in 4 of 6 patients $(66 \%)$; and $\mathrm{AUC}_{0-\mathrm{t}}$ values in the range of 401 to $600 \mu \mathrm{g} / \mathrm{h} / \mathrm{mL}$ resulted in complete suppression in 2 of 2 patients (100\%).

Two patients received comedication with ethosuximide, 5 with levetiracetam, 1 with topiramate, and 4 with valproic

Figure 3 Plasma concentration over time (mean \pm SD) for 3 ascending doses of cenobamate

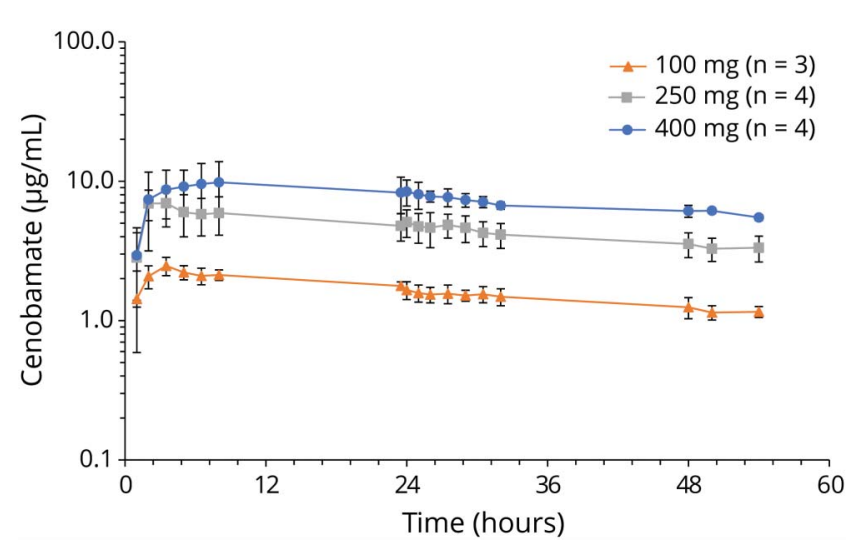

acid. There did not appear to be any clinically significant changes in serum concentration for any comedication.

\section{Safety}

No deaths, serious treatment-emergent AEs (TEAEs), or TEAEs leading to discontinuation occurred during this study. A total of 29 TEAEs were reported in 6 patients, and 24 TEAEs reported in 5 patients were considered treatment related by the investigator. Two severe TEAEs (blood pressure orthostatic decrease and syncope) occurred in 1 patient after administration of $400-\mathrm{mg}$ cenobamate. Nervous system disorders were the most reported class of TEAEs, with the most frequent TEAEs, postural dizziness and somnolence, both reported in 3 patients each. All TEAEs resolved by the end of the study. One patient had 13 of 29 (44.8\%) total TEAEs reported during this study. There did not appear to be any trends with regard to TEAEs increasing with dose level. There were no clinically meaningful changes from baseline in laboratory values, vital signs, physical examinations, 12-lead ECG, or mood assessment. Clinically significant postdose neurologic findings were reported in 2 patients, including gait disturbance, mild cognitive impairment, postural dizziness, mild/slight imbalance, inability to perform, and mild limited cognition.

\section{Discussion}

The current study used the photosensitivity proof-of-principle model to establish the potential for efficacy of cenobamate in patients with epilepsy. In this study, cenobamate decreased IPS sensitivity, with greater suppression of IPS-induced PPR response observed with higher doses (250 and $400 \mathrm{mg}$ ). In particular, the $250-\mathrm{mg}$ dose $(\mathrm{n}=4)$ produced complete or partial suppression of IPS sensitivity in all 4 evaluable patients.

When planned, this study was designed to include a 600-mg dose level to be administered to patients who completed the 400-mg dose level. The study was stopped after the 400-mg dose level because of reduced photosensitivity at doses of $100 \mathrm{mg}$ and because reduced and complete suppression of IPS at doses of 250 and $400 \mathrm{mg}$ had already been demonstrated. There was little reason to dose at the 600-mg dose level because of difficulty recruiting patients and the fact that reduced photosensitivity was already established at lower dose levels.

The photosensitivity model has been successful in identifying AEDs in early-phase development., ${ }^{3,7}$ Previous studies have shown a reduction in photosensitivity with almost all effective AEDs tested, despite differences in mechanisms of action. ${ }^{1,3,6,7,16,17}$ In this model, demonstrating a change from placebo confirms delivery of drug to the brain; therefore, it can be used as initial evidence of drug efficacy.

In the current study, on the basis of the geometric mean values, the $\mathrm{AUC}_{0-24}$ and $\mathrm{C}_{\max }$ parameters for each cohort appeared dose-proportional across a dose range of 100 to 
Table 3 Pharmacokinetic parameters for the 3 doses of cenobamate

\begin{tabular}{|c|c|c|c|}
\hline \multirow[b]{2}{*}{ Pharmacokinetic parameter } & \multicolumn{3}{|c|}{ Cenobamate treatment dose } \\
\hline & $100 \mathrm{mg}(\mathrm{n}=3)$ & $250 \mathrm{mg}(\mathrm{n}=4)$ & $400 \mathrm{mg}(n=4)$ \\
\hline $\mathrm{AUC}_{0-24}, \mu \mathrm{g} / \mathrm{h} / \mathrm{mL}(\%)^{\mathrm{a}}$ & $45.9(11.8)$ & $127(27.6)$ & $197(32.9)$ \\
\hline $\mathrm{AUC}_{0-\mathrm{t}}, \mu \mathrm{g} / \mathrm{h} / \mathrm{mL}(\%)^{\mathrm{a}}$ & $87.4(12.3)$ & $300(22.4)$ & $397(19.2)$ \\
\hline $\mathrm{AUC}_{0-\mathrm{inf}}, \mu \mathrm{g} / \mathrm{h} / \mathrm{mL}(\%)^{\mathrm{a}}$ & $174(12.3)$ & $623(40.1)$ & $986(13.3)$ \\
\hline$A \cup C_{0-\mathrm{t}} / A \cup C_{0-\text { inf }}, \%^{b}$ & $50.4 \pm 4.44$ & $54.4 \pm 29.4$ & $41.7 \pm 13.6$ \\
\hline $\mathrm{C}_{\max }, \mu \mathrm{g} / \mathrm{mL}(\%)^{\mathrm{a}}$ & $2.45(15.2)$ & $6.98(28.7)$ & $9.56(35.3)$ \\
\hline$t_{\max }, h^{c}$ & $3.47(3.47-3.50)$ & $2.77(1.97-3.45)$ & $7.91(2.02-8.00)$ \\
\hline$t_{1 / 2}, h^{b}$ & $52.0 \pm 7.98$ & $81.4 \pm 42.1$ & $74.1 \pm 22.8$ \\
\hline$k_{e l}, h^{-1 b}$ & $0.0135 \pm 0.0022$ & $0.0112 \pm 0.0075$ & $0.0103 \pm 0.0042$ \\
\hline \multicolumn{4}{|c|}{ 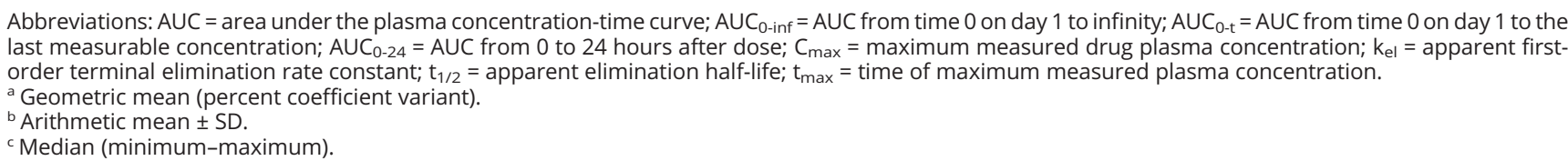 } \\
\hline
\end{tabular}

$400 \mathrm{mg}$, whereas nonproportional increases in the $\mathrm{AUC}_{0-\mathrm{t}}$ of cenobamate were exhibited. However, in this study, the small number of patients within each dosing cohort may have precluded a robust assessment of these parameters, as indicated by the low $\mathrm{AUC}_{0-\mathrm{t}} / \mathrm{AUC}_{0 \text {-inf }}$ ratio.
Pharmacokinetic characteristics of single (up to $750 \mathrm{mg}$ ) and multiple (50-300 mg) doses of cenobamate have been explored in studies in healthy volunteers. ${ }^{18}$ In these studies, cenobamate was associated with more than dose-proportional increases in AUC, especially after single-dose administration,

Table 4 Photosensitivity response and exposure for each patient

\begin{tabular}{|c|c|c|c|c|c|}
\hline Patient & $C_{\max }, \mu g / m L$ & $A U C_{0-24}, \mu g / h / m L$ & $A U C_{0-t}, \mu g / h / m L$ & $\mathrm{AUC}_{0-\text { inf }}, \mu \mathrm{g} / \mathrm{h} / \mathrm{mL}$ & Change in IPS sensitivity \\
\hline \multicolumn{6}{|c|}{ Cenobamate $100 \mathrm{mg}$} \\
\hline 1 & 2.10 & 40.4 & 75.9 & 146.56 & No change \\
\hline 2 & 2.47 & 46.9 & 92.4 & 166.51 & Partial suppression \\
\hline 3 & 2.84 & 51.01 & 95.1 & 182.68 & No change \\
\hline \multicolumn{6}{|c|}{ Cenobamate $250 \mathrm{mg}$} \\
\hline 4 & 4.96 & 88.3 & 308.0 & 294.36 & Partial suppression ${ }^{b}$ \\
\hline 5 & 9.88 & 170.0 & 406.0 & 519.34 & Complete suppression \\
\hline $6^{a}$ & 7.00 & 133.0 & 258.0 & 633.01 & Partial suppression ${ }^{b}$ \\
\hline 7 & 6.90 & 131.0 & 251.0 & 444.91 & Partial suppression \\
\hline \multicolumn{6}{|c|}{ Cenobamate $400 \mathrm{mg}$} \\
\hline $9^{a}$ & 8.92 & 178.0 & 364.0 & $1,050.49$ & No change \\
\hline $10^{\mathrm{a}}$ & 7.57 & 158.0 & 361.0 & $1,154.17$ & No change \\
\hline $11^{a}$ & 7.82 & 168.0 & 357.0 & 913.88 & Partial suppression \\
\hline $12^{\mathrm{a}}$ & 15.80 & 316.0 & 528.0 & 769.08 & Complete suppression \\
\hline
\end{tabular}

Abbreviations: $A \cup C=$ area under the plasma concentration-time curve; $A \cup C_{0-\text { inf }}=A U C$ from time 0 on day 1 to infinity; $A U C_{0-t}=A U C$ from time 0 on day 1 to the last measurable concentration; $A \cup C_{0-24}=A \cup C$ from 0 to 24 hours post-dose; $C_{\max }=$ maximum measured drug plasma concentration.

Patient 8 withdrew from the study.

a patient re-enrolled.

b Partial suppression was also reported in $\geq 1$ eye conditions. 
and a long half-life (55-60 hours) was exhibited within the 200- to $300-\mathrm{mg} / \mathrm{d}$ dose range.

When evaluated by dosing cohort, it appeared that, although the mean peak and extent of exposure to cenobamate were highest at the 400-mg dose level, the 250-mg dose level seemed to produce the greatest magnitude of suppression in IPS sensitivity. However, when evaluated by individual patients, higher cenobamate plasma concentrations produced greater suppression of IPS response. For example, $\mathrm{C}_{\max }$ values in the range of 1.0 to $4.0 \mu \mathrm{g} / \mathrm{mL}$ and $\mathrm{AUC}_{0-\mathrm{t}}$ values in the range of 1 to $200 \mu \mathrm{g} / \mathrm{h} / \mathrm{mL}$ resulted in partial suppression of IPS sensitivity in 1 of 3 patients $(33 \%) . C_{\max }$ values in the range of 4.1 to $9.0 \mu \mathrm{g} / \mathrm{mL}$ and $\mathrm{AUC}_{0-\mathrm{t}}$ values in the range of 201 to $400 \mu \mathrm{g} / \mathrm{h} /$ $\mathrm{mL}$ resulted in partial suppression of IPS sensitivity in 4 of 6 (66\%) patients. $C_{\max }$ values in the range of 9.1 to $16.0 \mu \mathrm{g} / \mathrm{mL}$ and $\mathrm{AUC}_{0-\mathrm{t}}$ values in the range of 401 to $600 \mu \mathrm{g} / \mathrm{h} / \mathrm{mL}$ resulted in complete suppression in 2 of 2 patients (100\%).

Single doses of cenobamate up to $750 \mathrm{mg}$ were found to be generally well tolerated in previous studies in healthy volunteers. ${ }^{18}$ In the current study, with doses up to $400 \mathrm{mg}$, there were no deaths, serious TEAEs, or TEAEs leading to discontinuation. Ongoing clinical trials in patients with focal seizures will help to further characterize the safety and tolerability profile of cenobamate. Similarly, the potential for drug-drug interactions with cenobamate and other AEDs will need further evaluation because the number of patients taking concomitant AEDs was small.

Although the results of this study should be interpreted cautiously because of the small number of patients and lack of formal statistical analysis, the findings shown in this clinical epilepsy model support a proof of principle for cenobamate in epilepsy. That most patients in this study also had a history of generalized epilepsy suggests that the photosensitivity model appears to screen for broad-spectrum antiseizure activity. Furthermore, a reduction in PPR demonstrated in the photosensitivity model, along with measurement of plasma concentrations of compounds, can help establish the pharmacokinetic/pharmacodynamic relationship and identify optimal doses and duration of treatment effects for investigational AEDs. ${ }^{2,7}$ In a meta-analysis, doses corresponding to $50 \%$ to $100 \%$ response in proof-of-concept photosensitivity trials were predictive, within 2 -fold, of the minimally efficacious doses of the AED. ${ }^{7}$ On the basis of the pharmacokinetic/ pharmacodynamic findings from the current proof-of-principle study of cenobamate, a dose of $200 \mathrm{mg}$ was included for further assessment in large phase 2 clinical trials in patients with focal seizures (ClinicalTrials.gov NCT01397968 and NCT01866111).

Cenobamate suppressed IPS-PPR response in patients with photosensitive epilepsy and was well tolerated in single doses up to $400 \mathrm{mg}$. These results indicate an efficacy signal for the treatment of patients with epilepsy and support the evaluation of cenobamate efficacy and safety in large clinical trials.

\section{Acknowledgment}

The authors thank Janet Peterson, PhD, of MedVal Scientific Information Services, LLC (Princeton, NJ, USA) for her medical writing contributions to the first draft. Medical writing and editing assistance were provided by MedVal Scientific Information Services, LLC (Princeton, NJ), which was funded by SK Life Science, Inc. SK Life Science, Inc performed the statistical analysis. This manuscript was prepared according to the International Society for Medical Publication Professionals' "Good Publication Practice for Communicating Company-Sponsored Medical Research: GPP3.”

\section{Study funding}

This study was funded by SK Life Science, Inc (Fair Lawn, NJ).

\section{Disclosure}

D.G.A. Kasteleijn-Nolst Trenite is a consultant/advisor for Idorsia, Otsuka, Ovid, and UCB. B.D. DiVentura is an employee of the Epilepsy Study Consortium, which has received research support, meeting support, and services from Acadia, Acorda, Adamas, Addex, Aeonian, Alexza, Anavex, Axcella, Axovant, Biogen, BioPharm Solutions, BioMotiv/Koutif, Blackfynn, Bloom Science, Bridge Valley Ventures, Cavion, Cerebral, Cerevel, Clinilabs, Concert, Covance, Crossject, CuroNZ, Eisai, Empatica, Engage, Epilepsy Foundation, Epitel, GlaxoSmithKline, GW Pharmaceuticals, Idorsia, Impax, Ionis, Johnson \& Johnson, Marinus, Medtronic, MonoSol Rx/ Aquestive, Monteris, Nestle-Health Science, Neurelis, NeuroPace, Novartis, Otsuka, Ovid, Pfizer, Pfizer-Neusentis, Praxis, Redpin, Sage, Sancilio, Shire, SK Life Science, Inc, SpringWorks, Stoke, Sunovion, Supernus, Takeda, UCB, Ultragenyx, Upsher-Smith, Vyera, West Therapeutic Development, Xenon, Xeris, Zogenix, and Zynerba. J. Pollard is a co-owner of Cognizance Biomarkers. G. Krauss is a consultant/advisor for Adamas, Eisai, Otsuka, Shire, and Vertex and has received research support from SK Life Science, Inc and UCB. S. Mizne is an employee of MedVal Scientific Information Services, which was contracted by SK Life Science, Inc for medical writing support. J. French receives New York University salary support from the Epilepsy Foundation and for consulting work and/or attending scientific advisory boards on behalf of the Epilepsy Study Consortium for Acadia, Adamas, Addex, Aeonian, Alexza, Anavex, Axcella Health, Axovant, Biogen, BioMotiv/ Koutif, Blackfynn, Bloom Science, Bridge Valley Ventures, Cavion, Cerebral Therapeutics, Cerevel, Clinilabs, Concert Pharmaceuticals, Covance, Crossject, CuroNZ, Eisai, Empatica, Engage Therapeutics, Epitel, GW Pharmaceuticals, Idorsia, Impax, Ionis, J\&J Pharmaceuticals, Marinus, MonoSol Rx, Neurelis, Novartis, Otsuka Pharmaceutical Development, Ovid Therapeutics Inc., Pfizer, Pfizer-Neusentis, Praxis, Redpin, Sage, Sancilio, Shire, SK Life Science, Inc, SpringWorks, Stoke, Sunovion, Supernus, Takeda, UCB, Ultragenyx, Upsher-Smith, Vyera, West Therapeutic Development, Xenon, Xeris, Zogenix, and Zynerba. J. French has also received research grants from Biogen, Cavion, Engage, Neurelis, Ovid, SK Life Science, Inc, $\mathrm{UCB}$, and Zogenix, as well as grants from the Epilepsy Research 
Foundation, Epilepsy Study Consortium, and National Institute of Neurological Disorders and Stroke. She is on the editorial board of Lancet Neurology and Neurology Today. She is scientific officer for the Epilepsy Foundation, for which New York University receives salary support. She has received travel reimbursement related to research, advisory meetings, or presentation of results at scientific meetings from the Epilepsy Study Consortium, the Epilepsy Foundation, Adamas, Axovant, Biogen, Blackfynn, CuroNZ, Eisai, Engage, Idorsia, Neurelis, Novartis, Otsuka, Ovid, Pfizer, Redpin, Sage, SK Life Science, Inc, Sunovion, Takeda, UCB, Ultragenyx, and Zynerba. Go to Neurology.org/ $\mathrm{N}$ for full disclosures.

\section{Publication history}

Received by Neurology October 31, 2018. Accepted in final form March 18, 2019.

Appendix Authors

\begin{tabular}{|c|c|c|c|}
\hline Name & Location & Role & Contribution \\
\hline $\begin{array}{l}\text { Dorothee G.A. } \\
\text { Kasteleijn- } \\
\text { Nolst Trenite, } \\
\text { MD, PhD, MPH }\end{array}$ & $\begin{array}{l}\text { University Medical } \\
\text { Center Utrecht, the } \\
\text { Netherlands; } \\
\text { Sapienza University, } \\
\text { Rome, Italy }\end{array}$ & Author & $\begin{array}{l}\text { Designed and } \\
\text { conceptualized } \\
\text { study; analyzed and } \\
\text { interpreted the data } \\
\text { after blinded EEG } \\
\text { readings; revised the } \\
\text { manuscript for } \\
\text { intellectual content }\end{array}$ \\
\hline
\end{tabular}

\begin{tabular}{|c|c|c|c|}
\hline $\begin{array}{l}\text { Bree D. } \\
\text { DiVentura, } \\
\text { MBA }\end{array}$ & $\begin{array}{l}\text { Epilepsy Study } \\
\text { Consortium, } \\
\text { Reston, VA }\end{array}$ & Author & $\begin{array}{l}\text { Analyzed and } \\
\text { interpreted the data, } \\
\text { revised the } \\
\text { manuscript for } \\
\text { intellectual content }\end{array}$ \\
\hline
\end{tabular}

\begin{tabular}{|c|c|c|c|}
\hline $\begin{array}{l}\text { John R. Pollard, } \\
\text { MD }\end{array}$ & $\begin{array}{l}\text { University of } \\
\text { Pennsylvania, } \\
\text { Philadelphia }\end{array}$ & Author & $\begin{array}{l}\text { Major role in } \\
\text { acquisition of data; } \\
\text { interpreted the dat }\end{array}$ \\
\hline
\end{tabular}
Philadelphia interpreted the data; revised the manuscript for intellectual content

\begin{tabular}{|c|c|c|c|}
\hline $\begin{array}{l}\text { Gregory L. } \\
\text { Krauss, MD }\end{array}$ & $\begin{array}{l}\text { Johns Hopkins } \\
\text { University, } \\
\text { Baltimore, MD }\end{array}$ & Author & $\begin{array}{l}\text { Major role in } \\
\text { acquisition of data; } \\
\text { interpreted the data; } \\
\text { revised the } \\
\text { manuscript for } \\
\text { intellectual content }\end{array}$ \\
\hline
\end{tabular}

\begin{tabular}{|c|c|c|c|}
\hline $\begin{array}{l}\text { Sarah Mizne, } \\
\text { PharmD }\end{array}$ & $\begin{array}{l}\text { MedVal Scientific } \\
\text { Information } \\
\text { Services, Princeton, } \\
\text { NJ }\end{array}$ & Author & $\begin{array}{l}\text { Wrote initial } \\
\text { manuscript draft } \\
\text { based on input from } \\
\text { the other authors; } \\
\text { revised the } \\
\text { manuscript for } \\
\text { intellectual content } \\
\text { under their } \\
\text { guidance }\end{array}$ \\
\hline $\begin{array}{l}\text { Jacqueline A. } \\
\text { French, MD }\end{array}$ & $\begin{array}{l}\text { Epilepsy Study } \\
\text { Consortium, } \\
\text { Reston, VA; NYU } \\
\text { Langone } \\
\text { Comprehensive } \\
\text { Epilepsy Center, } \\
\text { New York, NY }\end{array}$ & Author & $\begin{array}{l}\text { Major role in } \\
\text { acquisition of data; } \\
\text { interpreted the data; } \\
\text { revised the } \\
\text { manuscript for } \\
\text { intellectual content }\end{array}$ \\
\hline
\end{tabular}

\section{References}

1. Binnie CD, Kasteleijn-Nolst Trenite DG, De Korte R. Photosensitivity as a model for acute antiepileptic drug studies. Electroencephalogr Clin Neurophysiol 1986;63: $35-41$.

2. Di Prospero NA, Gambale JJ, Pandina G, et al. Evaluation of JNJ-26489112 in patients with photosensitive epilepsy: a placebo-controlled, exploratory study. Epilepsy Res 2014;108:709-716.

3. Kasteleijn-Nolst Trenite D, Genton P, Brandt C, Reed RC. The "photosensitivity model" is (also) a model for focal (partial) seizures. Epilepsy Res 2017;133:113-120.

4. Lu Y, Waltz S, Stenzel K, Muhle H, Stephani U. Photosensitivity in epileptic syndromes of childhood and adolescence. Epileptic Disord 2008;10:136-143.

5. Kasteleijn-Nolst Trenite DG, van Emde Boas W, Groenhout CM, Meinardi H. Preliminary assessment of the efficacy of Org 6370 in photosensitive epileptic patients: paradoxical enhancement of photosensitivity and provocation of myoclonic seizures. Epilepsia 1992;33:135-141.

6. Kasteleijn-Nolst Trenite DG, Marescaux C, Stodieck S, Edelbroek PM, Oosting J. Photosensitive epilepsy: a model to study the effects of antiepileptic drugs: evaluation of the piracetam analogue, levetiracetam. Epilepsy Res 1996;25:225-230.

7. Yuen ES, Sims JR. How predictive are photosensitive epilepsy models as proof of principle trials for epilepsy? Seizure 2014;23:490-493.

8. Nakamura M, Shin H, Jang IS. Mechanism of action of cenobamate: preferential inhibition of the persistent sodium current. Neurology 2018;90(suppl 15):P5.278. Abstract.

9. Younus I, Reddy DS. A resurging boom in new drugs for epilepsy and brain disorders. Expert Rev Clin Pharmacol 2018;11:27-45.

10. Zaccara G, Schmidt D. Do traditional anti-seizure drugs have a future? A review of potential anti-seizure drugs in clinical development. Pharmacol Res 2016;104: $38-48$.

11. Bialer M, Johannessen SI, Levy RH, Perucca E, Tomson T, White HS. Progress report on new antiepileptic drugs: a summary of the Eleventh EILAT Conference (EILAT XI). Epilepsy Res 2013;103:2-30.

12. Kasteleijn-Nolst Trenite D, Brandt C, Mayer T, et al. Dose-dependent suppression of human photoparoxysmal response with the competitive AMPA/kainate receptor antagonist BGG492: clear PK/PD relationship. Epilepsia 2015;56:924-932.

13. French JA, Krauss GL, Kasteleijn D, DiVentura BD, Bagiella E. Effects of marketed antiepileptic drugs and placebo in the human photosensitivity screening protocol. Neurotherapeutics 2014;11:412-418.

14. Bond A, Lader $\mathrm{M}$. The use of analogue scales in rating subjective feelings. $\mathrm{Br} \mathrm{J}$ Med Psychol 1974;47:211-218.

15. Scheffer IE, Berkovic S, Capovilla G, et al. ILAE classification of the epilepsies: position paper of the ILAE Commission for Classification and Terminology. Epilepsia 2017;58:512-521.

16. Kasteleijn-Nolst Trenite DG, Genton P, Parain D, et al. Evaluation of brivaracetam, a novel SV2A ligand, in the photosensitivity model. Neurology 2007;69:1027-1034.

17. Kasteleijn-Nolst Trenite DG, French JA, Hirsch E, et al. Evaluation of carisbamate, a novel antiepileptic drug, in photosensitive patients: an exploratory, placebo-controlled study. Epilepsy Res 2007;74:193-200.

18. Vernillet L, Kamin M. Pharmacokinetics of cenobamate (YKP3089): results from single and multiple oral rising-dose studies in healthy subjects. Neurology 2018; 90(suppl 15):P5.280. Abstract. 


\section{Neurology}

\section{Suppression of the photoparoxysmal response in photosensitive epilepsy with cenobamate (YKP3089)}

Dorothee G.A. Kasteleijn- Nolst Trenite, Bree D. DiVentura, John R. Pollard, et al. Neurology 2019;93;e559-e567 Published Online before print July 10, 2019

DOI 10.1212/WNL.0000000000007894

This information is current as of July 10, 2019

\section{Updated Information \&} Services

References

Citations

Subspecialty Collections

Permissions \& Licensing

Reprints including high resolution figures, can be found at: http://n.neurology.org/content/93/6/e559.full

This article cites 18 articles, 1 of which you can access for free at: http://n.neurology.org/content/93/6/e559.full\#ref-list-1

This article has been cited by 1 HighWire-hosted articles: http://n.neurology.org/content/93/6/e559.full\#\#otherarticles

This article, along with others on similar topics, appears in the following collection(s):

\section{All Clinical trials}

http://n.neurology.org/cgi/collection/all_clinical_trials

All Epilepsy/Seizures

http://n.neurology.org/cgi/collection/all_epilepsy_seizures

Antiepileptic drugs

http://n.neurology.org/cgi/collection/antiepileptic_drugs

EEG

http://n.neurology.org/cgi/collection/eeg_

Information about reproducing this article in parts (figures,tables) or in its entirety can be found online at:

http://www.neurology.org/about/about_the_journal\#permissions

Information about ordering reprints can be found online:

http://n.neurology.org/subscribers/advertise

Neurology ${ }^{\circledR}$ is the official journal of the American Academy of Neurology. Published continuously since 1951, it is now a weekly with 48 issues per year. Copyright Copyright ( 2019 The Author(s). Published by Wolters Kluwer Health, Inc. on behalf of the American Academy of Neurology.. All rights reserved. Print ISSN: 0028-3878. Online ISSN: 1526-632X.

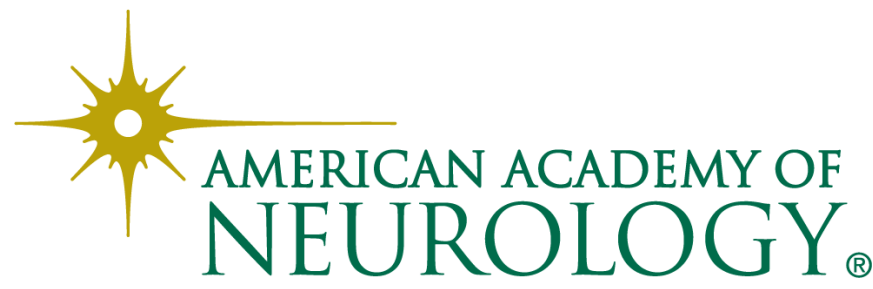

